\title{
6
}

\section{ENTRE BOLHAS E GRIETAS: A POLARIZAÇÃO POLÍTICO-IDEOLÓGICA NAS REDES SOCIAIS}

\section{BETWEEN BUBBLES AND RIFTS:POLITICAL IDEOLOGICAL POLARIZATION ON SOCIAL NETWORKS}

Fábio Barbosa de Lima1 Universidade de São Paulo / Fatec Itaquaquecetuba

Resumo: Neste artigo, temos por objetivo apresentar considerações acerca de parte dos resultados de nosso estudo doutoral (LIMA, 2019) que se insere no campo da Pragmática Sociocultural ao analisar os fenômenos bolha e grieta nas interações em publicações de temática político-ideológica na rede social Facebook no Brasil e na Argentina, respectivamente, e seus desdobramentos para os estudos da descortesia em uma perspectiva comparada. Para o escopo teórico de nosso estudo, recorremos aos escritos sobre os estudos da descortesia realizados por Culpeper (2011), Kaul de Marlangeon (2008) e Cordisco e Kaul de Marlangeon (2014). Os resultados alcançados apontam que o cenário político na atualidade favorece a oposição "nós contra eles" e que os comportamentos descorteses assumem a função de fomentar a discussão, marcando a polarização nas redes sociais.

Palavras-Chave: Descortesia; Política; Facebook; Brasil; Argentina.

1 Endereço eletrônico: fblima.fatec@gmail.com.

63 № 67, JUL-DEZI 2020, Salvador: pp. 63-81 


\begin{abstract}
In this article, we aim to present considerations about part of the results of our doctoral study (LIMA, 2019) which is inserted in the field of Sociocultural Pragmatics. We analyse the bubble and rift phenomena in interactions in publications with a political-ideological theme on the social network Facebook in Brazil and Argentina respectively and their consequences for the studies of Impoliteness in a comparative perspective. For the theoretical scope of our study, we resorted to the writings on the Studies of Impoliteness carried out by Culpeper (2011), Kaul de Marlangeon (2008) and Cordisco and Kaul de Marlangeon (2014). The results achieved point out that the political scenario nowadays favors the opposition "us against them" and the discourteous behaviors assume the role of fostering discussion, marking the polarization in social networks.
\end{abstract}

Keywords: Impoliteness; Policy; Facebook; Brazil; Argentina.

\title{
INTRODUÇÃO
}

No presente artigo, trazemos reflexões acerca de parte dos resultados obtidos na tese de doutorado² intitulada Nós contra eles: a descortesia no contexto político-ideológico na rede social Facebook no Brasil e na Argentina. Neste trabalho, foi realizada, a partir da análise dos corpora, a descrição, análise e comparação das diferenças na elaboração linguística das manifestações de descortesia em interações de publicações com temática político-ideológica na rede social Facebook em ambas culturas.

Faremos, assim, apontamentos sobre os fenômenos bolha e grieta, que simbolizam a polarização político-ideológica manifestada nas redes sociais no Brasil e na Argentina, respectivamente. Tal polarização, embora sempre presente, assume novos contornos na contemporaneidade. O enfrentamento direto, a intolerância, a negação de opinião do outro e a formação de comunidades ideologicamente posicionadas, são algumas das manifestações que podemos observar no cotidiano. Contudo, é inegável que a ascensão das redes sociais dá uma nova configuração a esses enfrentamentos, amplificando a sua dimensão e

2 Tese de Doutorado apresentada ao Programa de Pós-Graduação em Língua Espanhola e Literaturas Espanhola e Hispano-Americana, do Departamento de Letras Modernas da Faculdade de Filosofia, Letras e Ciências Humanas da Universidade de São Paulo, sob a orientação da Profa. Dra. María Zulma Moriondo Kulikowski. 
alcance.

Jenkins (2008, p. 27), afirma que a internet é o local em que "as velhas e as novas mídias colidem, onde mídia corporativa e mídia alternativa se cruzam, onde o poder do produtor de mídia e o poder do consumidor interagem de maneiras imprevisíveis". Observamos, assim, que a internet abriu novas práticas discursivas e que seus usuários têm se apropriado dessas novas possibilidades de interação, com grande destaque para as discussões no âmbito políticoideológico.

\section{AS REDES SOCIAIS COMO CAMPO DE ESTUDOS SOBRE A DESCORTESIA}

As redes sociais têm se tornado um campo importante para os estudos de Pragmática Sociocultural. Isso se deve ao seu impacto nas interações humanas e nas novas formas de se comunicar. Ainda que haja falta de marcas de contexto e que a ausência da interação face a face possa levar os interagentes a um uso exagerado da cortesia; observamos que, por outro lado, esses mesmos aspectos podem levá-los a comportamentos mais próximos da descortesia.

Para Culpeper, descortesia é

uma atitude negativa em relação a comportamentos específicos que ocorrem em contextos específicos. É sustentado por expectativas, desejos e/ou crenças sobre a organização social, incluindo, em particular, como a identidade de uma pessoa ou de um grupo é mediada por outros em interação. Alguns comportamentos são vistos negativamente - considerados "descorteses" quando ocorre o conflito com a forma como se espera que sejam, como se quer que sejam e/ou como se pensa que deveriam ser. Tais comportamentos sempre têm ou presumem que tenham consequências emocionais para pelo menos um participante, ou seja, causam ou devem causar ofensa. Vários fatores podem exacerbar o quão ofensivo um comportamento indelicado é considerado, incluindo, por exemplo, se alguém entende um comportamento fortemente intencional ou não. (CULPEPER, 2011, p. 23) (tradução nossa) ${ }^{3}$

3 Citação original: Impoliteness is a negative attitude towards specific behaviours occurring in specific contexts. It is sustained by expectations, desires and /or beliefs about social organization, 
A descortesia, assim como a cortesia, é considerada uma estratégia comunicativa. Podemos afirmar que cortesia e descortesia estão em lados opostosde um continuum, sendo que um ato de fala pode variar para mais cortês ou maisdescortês.

Sendo assim, consideramos a cortesia e a descortesia como:

(...) partes do mesmo continuum, isto é, duas valorações opostas da mesma função, conceito que nos permite abarcar naturalmente ambos os fenômenos, sem considerá-los como simples opostos polares (...) mas como extremos deuma gradação. (KAUL DE MARLANGEON, 2008, p. 256) (tradução nossa) ${ }^{4}$

No âmbito da descortesia de fustigação, temos as estratégias de afiliação exacerbada e de refratariedade, que são paralelos traçados por Kaul de Marlangeon (2005) para as categorias de autonomia e afiliação propostas por Bravo (1999). Dessa forma, a afiliação exacerbada corresponde ao conceito de afiliação, o desejo de ser parte integrante do grupo, de usar a descortesia como defesa desse grupo. Já a refratariedade corresponde ao conceito de autonomia, de ser visto como alguém independente do grupo.

Cordisco e Kaul de Marlangeon (2014), detalham a relação entre esses dois conteúdos de imagem, a afiliação exacerbada e a refratariedade:

Na primeira (afiliação exarcebada), o indivíduo produz atividades nas quais se percebe e é percebido pelos outros como um membro do grupo. Oadepto assume sua filiação com plena consciência e orgulho: é partidário dos membros e das ideias de seu grupo, a ponto de escolher a descortesia em

including, in particular, how one person's or a group's identities are mediated by others in interaction. Situated behaviours are viewed negatively - considered 'impolite' - when they conflict with how one expects them to be, how one wants them to be and/or how one thinks they ought to be. Such behaviours always have or are presumed to have emotional consequences for at least one participant, that is, they cause or are presumed to cause offence. Various factors can exacerbate how offensive an impolite behaviour is taken to be, including for example whether one understands a behaviour to be strongly intentional or not. (CULPEPER, 2011, p. 23)

4 Citação original: partes del mismo continuo, o sea, dos valuaciones opuestas de la misma función, concepto que permite abarcar naturalmente ambos fenómenos, sin plantearlos como simples opuestos polares (...) sino como extremos de una gradación." (KAUL DE MARLANGEON, 2005, p. 256) 
sua defesa. No segundo (refratariedade), o indivíduo se percebe e é percebido pelos outros como opositor do grupo. Ele critica, reprova, ataca, combate, agride, quer expressar que está em uma atitude refratária em relação ao que lhe suscita oposição. (CORDISCO; KAUL DE MARLANGEON, 2014, p. 147) (tradução nossa) ${ }^{5}$

Considerada como estratégia comunicativa, a descortesia hoje não mais representa a quebra da interação, mas, sim, a estimula, ao elevar o tom e mantera discussão. No que diz respeito aos embates no contexto políticoideológico nas interações na virtualidade, objeto de nosso estudo, Cordisco e Kaul de Marlangeon (2014), consideram a descortesia de fustigação como um mecanismo de pertencimento ou oposição ao grupo, caracterizando, assim, as posturas de afiliação exacerbada e de refratariedade, comportamentos que são o fio condutorda polarização nas redes sociais.

\section{ENTRE BOLHAS E GRIETAS: A POLARIZAÇÃO NAS REDESSOCIAIS}

A polarização política recente está em vários espaços e não seria diferente com as redes sociais. É notório que esse fenômeno alcançou sua maior expressão na virtualidade. No Brasil e na Argentina dois vocábulos assinalam esse antagonismo político: do lado brasileiro temos a expressão bolha e do lado argentino a expressão grieta.

A ideia de bolha no Brasil representa o movimento dos indivíduos e grupos que se voltam para si e veem o outro lado do espectro político-ideológico

\footnotetext{
5 Citação original: En la primera (afiliación exarcebada), el individuo produce actividades en las que se percibe a sí mismo y es percibido por los demás como adepto a un grupo. El adepto asume su calidad de miembro con plena conciencia y orgullo: es partidario de los miembros y de las ideas de su grupo, al punto de escoger la descortesía en su defensa. En la segunda (refractariedad), el individuo se percibe a sí mismo y es percibido por los demás como opositor al grupo. Critica, vitupera, arremete, combate, agrede, quiere expresar que está en una actitud refractaria respecto de aquello que suscita su oposición. (CORDISCO; KAUL DE MARLANGEON, 2014, p. 147)
} 
como inimigo; muitas vezes, indo além, ao negar a legitimidade da oposição.

Na Argentina, por sua vez, o termo que dá sentido à polarização é la grieta, que foi cunhado pelo jornalista Jorge Lanata. Antes de sua aplicação ao universo das redes sociais, assumiu significado nos meios de comunicação em que, na conjuntura da presidência de Cristina Kirchner, os grupos contrários ao governo foram tachados como "medios hegemónicos" e os favoráveis, como "oficialistas". (CUÉ, 2015, s/p). Posteriormente, essa cisão alcançou também a virtualidade e persiste até os dias atuais.

Análises e representações gráficas dos fenômenos bolha/grieta são usuais na imprensa dos dois países. Do lado brasileiro, selecionamos uma pintura da artista plástica Camila Sproesser para a matéria Redes sociais criam bolhas ideológicas inacessíveis a quem pensa diferente (ZUCKERMAN, 2017), publicada no caderno Ilustríssima, da Folha de São Paulo, em 2017.

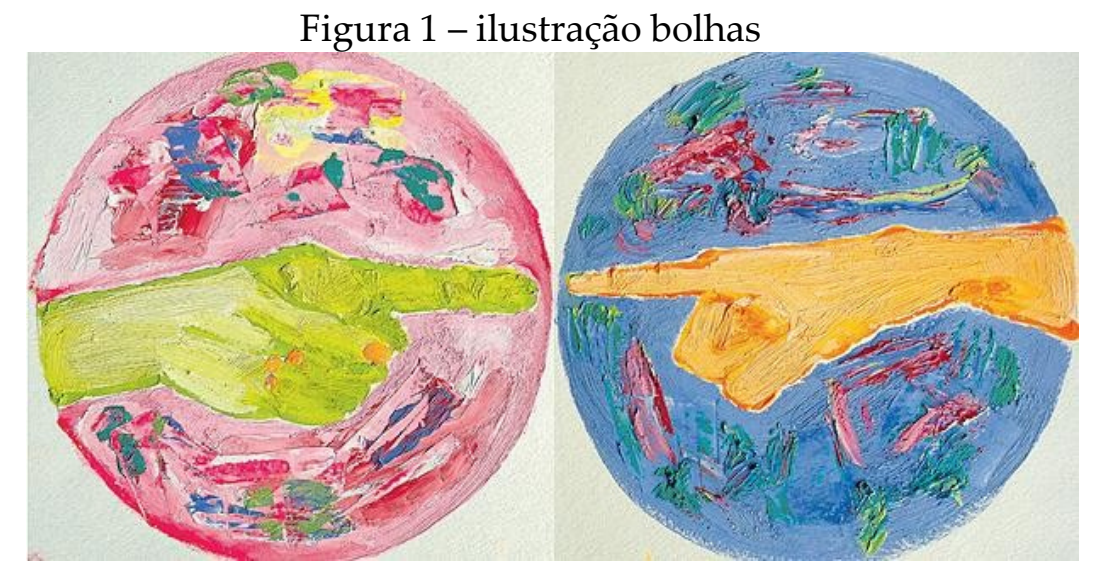

Fonte: Folha de São Paulo (2017)

A representação consiste em duas bolhas, a vermelha posicionada à esquerda e a azul, à direita; em cada bolha há uma mão que aponta o dedo indicador para a bolha oposta, porém, esse gesto não rompe a bolha. Temos, então, a representação do enfrentamento nas redes sociais, mas não ocorre o esperado rompimento das bolhas. 
Do lado argentino, temos uma charge de autor desconhecido, que ilustra a coluna "La grieta" que nos separa a los argentinos (MATEO, 2017), publicada no jornal on-line Diario Prensa, também em 2017. Essa imagem aparece ainda em outros textos publicados em blogs.

Figura 2 - ilustração grieta

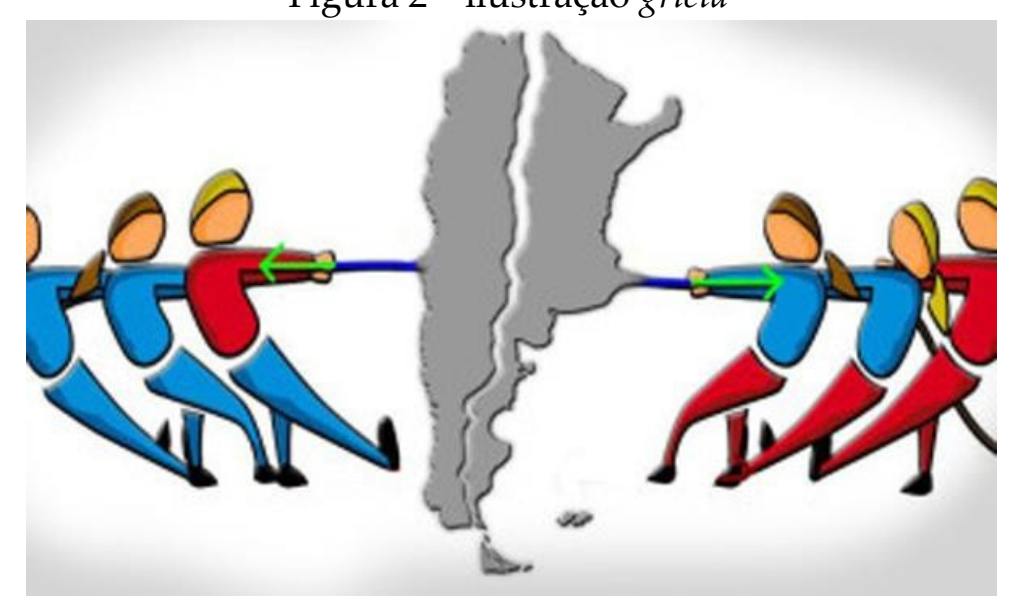

Fonte: DiarioPrensa.Com.Ar (2017)

Na imagem vemos o mapa da Argentina em cinza, com uma fenda longitudinal, e três pessoas de cada lado puxando parte do país em direções opostas. Temos, assim, representada a ideia de divisão do país, sem a possibilidade de cerrar la grieta.

Essa cisão na sociedade e, consequentemente, nas interações nas redes sociais, pode - em certa medida - ser explicada pela adoção de um sistema de algoritmos pelo Facebook no final dos anos 2000. A rede social aprende de acordo com o uso que as pessoas fazem da plataforma, levando em conta as ações de reagir ao conteúdo, comentar, compartilhar e bloquear conteúdos para exibir a cada um dos usuários o que seria relevante para ele.

Desse modo, podemos afirmar que há uma coprodução do conteúdo, nessa conjunção entre o usuário e o algoritmo. Se de um lado há a ideia de oferecer o que o indivíduo deseja ver, por outro há aformação de bolhas, causa e efeito da polarização. 
É importante o questionamento sobre o papel das redes sociais. Temos visto ao longo dos últimos anos o seu alcance na movimentação política dos países, mas cabe perguntar se constituem uma nova agenda ou apenas reproduzem as agendas dos meios de comunicação, o que pode contribuir para a permanência da sensação de viver fechados em bolhas ou separados por grietas.

O comportamento dos usuários nas redes sociais foi objeto de um estudo realizado pela consultoria argentina Solo Comunicación e publicado pelo jornal Clarín (2017). Nessa pesquisa, mil duzentos e cinquenta indivíduos residentes na Província de Buenos Aires foram entrevistados por telefone sobre a polarização política nas redes sociais na Argentina. Desse total, 73,5\% são usuários das redes sociais e em torno de $60 \%$ afirmam que as redes sociais aprofundam as diferenças políticas.

Questionados sobre qual a rede em que as diferenças são mais evidentes, 42,6\%dos entrevistados reconhecem como sendo do Facebook este posto; mais que o dobro da segunda rede mais citada, o Twitter, com 19\%, como podemos conferir no gráfico abaixo.

Figura 3 - Gráfico Pesquisa Solo Comunicación

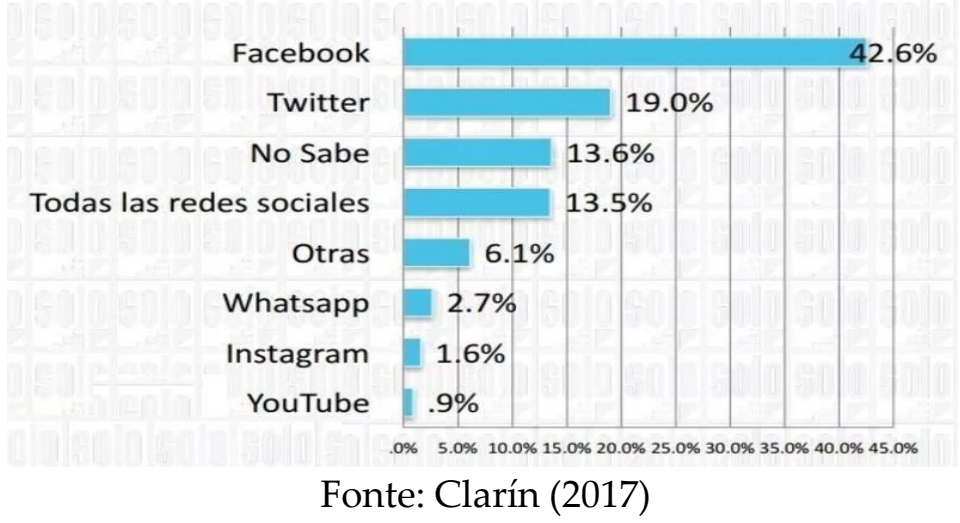

Nos últimos anos, tanto no Brasil quanto na Argentina, as redes sociais retroalimentam as manifestações de rua. No caso do Brasil, que teve o boom das manifestações em junho de 2013, além da convocação pública para a participação 
nas manifestações, as curtidas e os compartilhamentos de conteúdos gerados, tanto pela imprensa como por indivíduos em iniciativa própria, ofereciam, cada vez mais, conteúdos marcados pela polarização.

Sobre as manifestações brasileiras, Ribeiro aponta que:

Essa estrutura polarizada tem uma história. Ela se formou durante os oito oudez meses que se seguiram às manifestações de junho de 2013, durante as quais as páginas do Facebook com maior número de interações foram as de produção de conteúdo anticorrupção. Essas páginas, até então, estavam posicionadas entre as páginas de esquerda e de direita. Muitos de seus leitores se juntaram aos ativistas que se manifestavam contra o aumento de passagens trazendo consigo um conjunto mais difuso de pautas anticorrupção e por mais direitos sociais. (...) essa recém-formada esfera pública se cindiu ainda naquele ano, afastando da esquerda grande parte daqueles que foram às ruas pela primeira vez e aproximando-os da direita. Esse deslocamento está na gênese do campo antipetista. (RIBEIRO, 2018, p. 86)

Viana (2018), apresenta um estudo realizado para a agência A Pública em que foram analisadas as interações entre 1822 perfis de Facebook e páginas de notícias no Brasil, revelando que há diferenças significativas entre os leitores de páginas engajadas, que marcam a polarização do debate político - à direita e à esquerda - e os leitores de páginas da imprensa tradicional; mostrando a tendência entre os jovens (entre 21 e 30 anos) de se afastar de páginas engajadas e interagir com a imprensa tradicional. A percepção dos entrevistados é que as páginas da imprensa tradicional adotam um tom mais neutro em seus textos.

O Monitor do Debate Político no Meio Digital ${ }^{6}$ classifica as páginas em três grandes grupos: a imprensa tradicional, os sites engajados de esquerda e os sites engajados de direita. No espectro da imprensa tradicional temos as páginas dos jornais Folha de São Paulo, O Globo, Estadão, dasrevistas Veja, IstoÉ, Exame,

\footnotetext{
6 Monitor do debate político no meio digital: projeto coordenado Mônica Mourão, Vinicius Carvalho e José Brito (ESPM-RJ) e Marcio Moretto e Pablo Ortellado (USP), que busca mapear, mensurar e analisar o ecossistema de debate político no meio digital. Disponível em http://www.monitordigital.org Acessado em 20/04/2019.
} 
Época e Carta Capital e dos portais do UOL Notícias e G1; já nos sites engajados de esquerda temos as páginas Jornal GGN, Diário do Centro do Mundo, Falando Verdades, Cafezinho, Brasil 247 e Mídia Ninja e da Revista Fórum; por fim, nos sitesengajados de direita, temos Jornalivre, Papo TV, Folha Política, Partido AntiPT e Anti-PT.

Nessa pesquisa, foram recolhidos os dados de vinte e duas páginas no dia 10 de maio de 2017, quando houve cerca de 2,2 milhões de curtidas por cerca de 880 mil usuários nas publicações. Partindo desse ponto, foram sorteados aleatoriamente cerca de 600 usuários de cada um dos grupos para catalogar as informações demográficas como gênero, idade, estado e escolaridade de cada um dos perfis. O resultado está no grafo abaixo, em que se pode observar três aglomerados bem distintos e polarizados.

Figura 4 - grafo: acesso às páginas de notícias no Brasil

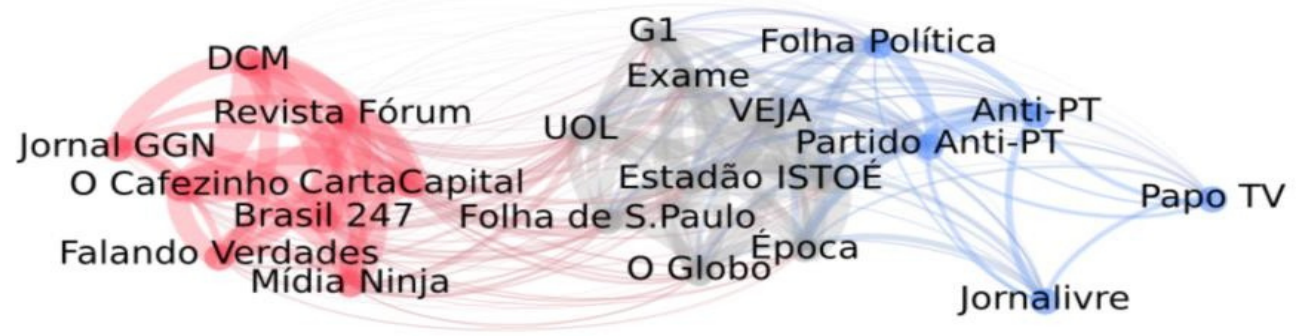

Fonte: Viana (2018)

Temos os dois polos - sites engajados de esquerda e direita - e o encontro dos leitores desses extremos se dá nas páginas da considerada imprensa tradicional, ao centro. Essa convergência, no entanto, não significa o rompimento da bolha.

Estudo semelhante foi realizado na Espanha, pela Social Media + Society (SÁEZ, 2018), indica que o ponto de encontro para grupos muito polarizadosé a grande imprensa, que exerce o papel de mediação entre as bolhas. No caso espanhol esse papel é desempenhando por veículos como La Vanguardia, El 
Mundo ou El País. Entretanto, tal confluência de público não significa atenuação da polarização. No fim das contas, nesse encontro nas redes se multiplicam os confrontos entre as pessoas que pensam de forma distinta, como veremos adiante.

\section{O COMPORTAMENTO NAS REDES SOCIAIS E A FORMAÇÃO DE BOLHAS E GRIETAS}

Esses dados sobre o comportamento dos usuários nas redes sociais foram essenciais para a conformação de nossos corpora, considerando que o Facebook é reconhecidocomo o espaço na virtualidade em que mais acontecem confrontos de cunho político-ideológico entre as redes sociais. Há, ainda, que considerar a busca por parte considerável do público pelas páginas da considerada grande imprensa, pela sensação de ter uma informação mais neutra. Decidimos, então, por estabelecer as interações de cunho político-ideológico no Facebook de páginas de grande alcance - UOL e Carta Capital no Brasil e Clarín e Página 12 na Argentina, como nosso objeto de estudo.

A partir da análise de elementos dos corpora coletados, foi concebido o teste de hábitos sociais, a fim de verificar se os resultados de nossa análise são percebidos e/ou confirmados pelos usuários da rede social. Esse instrumento é de grande valia para os estudos de Pragmática Sociocultural.

Em uma pesquisa no âmbito da Pragmática Sociocultural, o uso de testes de hábitos sociais constitui importante ferramenta, pois "(...) nos ajuda a nos aproximarmos das percepções que os falantes têm sobre o que é ser descortês" (BERNAL, 2006, p. 623), (tradução nossa)7.

Dessa forma, podemos afirmar que o objetivo dos testes de hábitos sociais é, em lugar de recorrer a explicações supostamente universais, destacar a

\footnotetext{
7 Citação original: (...) nos ayuda a acercarnos a las percepciones que los hablantes tienen sobre qué es ser descortés. (BERNAL, 2006, p. 623)
} 
importância de explicar a cortesia segundo as características do contexto cultural, para assim confirmar e apoiar as interpretações feitas a partir da análise dos dados obtidos. A este respeito, Hernández Flores (2003), propõe que esses testes constituam uma ferramenta por meio da coleta de impressões e comentários de informantes sobre o material de estudo; assim pode-se conhecer como é avaliado e interpretado pelos membros da comunidade um comportamento comunicativo. Tal direcionamento coincide com os objetivos delineados em nosso trabalho.

Nosso teste foi elaborado em português e espanhol, para ser aplicado aos falantes das duas línguas em seus respectivos países e as perguntas de análise foram precedidas do levantamento dos dados sociológicos dos informantes, como idade, gênero, cidade de nascimento, cidade de residência, escolaridade e ocupação.

Murillo (2006) aponta que essas informações são essenciais para que seja possível obter uma amostra confiável e significativa, sendo que devem ser “definidas as variáveis sociais relevantes para a análise posterior e interpretação dos dados: classificações etárias, nível de instrução, representatividade de gênero e representatividade geográfica, como mínimo" (2006, p. 67, tradução nossa) ${ }^{8}$.

Para atender às necessidades de nossa análise, estabelecemos como critérios exigidos para participar da pesquisa ser maior de dezoitos anos, ter conta ativa no Facebook, ser brasileiro residente no Brasil ou argentino residentena Argentina.

Nossa amostra foi composta por cem informantes de cada país e nos concentramos nas respostas obtidas de pessoas entre 20 e 50 anos. A média de idade dos respondentes brasileiros é de 30,4 anos e dos argentinos, 29,1. No que

\footnotetext{
8 Citação original: definidas las variables sociales relevantes para el posterior análisis e interpretación de los datos: rangos etarios, nivel de instrucción, representatividad de género y representatividad geográfica, como mínimo. (MURILLO, 2006, p. 67)
} 
diz respeito à proporção de gêneros temos a seguinte conformação: do lado brasileiro temos $69 \%$ dos informantes do gênero feminino, 30\% do gênero masculino e $1 \%$ se identificou como outro. Do lado argentino as proporções são $71 \%$ do gênero feminino, $27 \%$ do gênero masculino e $2 \%$ identificado como outro. Observamos, assim, que há equilíbrio em relação ao gênero de nossos informantes nos dois países.

Nosso questionário foi composto por dezoito questões fechadas apresentadas após as questões de identificação dos informantes. As três primeiras questões dizem respeito à participação dos indivíduos nas redes sociais, em particular no Facebook. Os dados obtidos dizem respeito ao tempo de conta ativa no Facebook, se tem conta ativa em outras redes sociais e qual a sua frequência de acesso. Destacamos o resultado da questão 1, que indaga sobre o tempo de conta ativa no Facebook: $92 \%$ dos brasileiros e $85 \%$ dos argentinos entrevistados mantêm conta ativa nesta rede social há mais de 5 anos.

O segundo bloco de perguntas de nosso estudo nos interessa particularmente na presente análise. Um conjunto de seis questões foi pensado para verificar a percepção do usuário em relação à polarização política no Facebook, do qual destacamos duas questões que podem nos indicar elementos sobre o fenômeno bolha/grieta em ambas as sociedades.

Perguntamos sobre o hábito de se informar pelo Facebook ou por outras redes sociais. Para tanto, usamos os marcadores de frequência sempre, com frequência, às vezes e nunca. Nos gráficos abaixo (fig. 5 e fig. 6) podemos observar os resultados. 
Figura 5 - gráfico questão 4 - português

4. Você costuma se informar pelo Facebook e/ou por outras redes sociais? 100 respostas

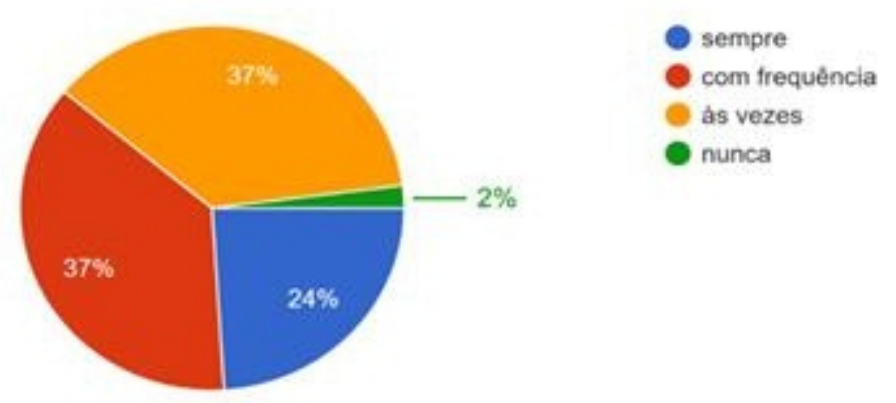

Fonte: Lima (2019)

Do lado brasileiro, 37\% dos brasileiros afirmaram que se informam pelo Facebook e/ou outras redes sociais com frequência; igual porcentagem o fazem às vezes, seguido por $24 \%$ dos informantes que sempre se informam por redes sociais e apenas $2 \%$ que nunca se informam dessa maneira.

Figura 6 - gráfico questão 4 - espanhol

\section{4. ¿Solés informarte por Facebook y/o por otras redes sociales?}

100 respostas

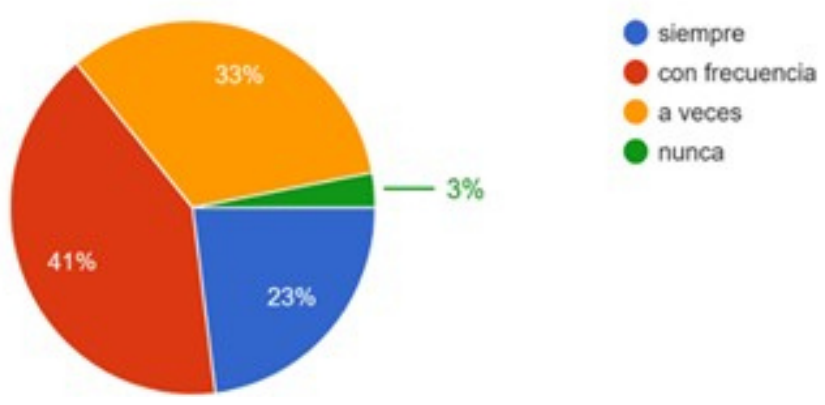

Fonte: Lima (2019)

Já do lado argentino, 41\% dos informantes responderam que com frequência se informam pelo Facebook e/ou outras redes sociais; 33\% às vezes, seguido por 
23\% de indivíduos que sempre se informam por redes sociais e, por fim, 3\% nunca se informam dessa forma.

Observamos que os números são semelhantes, com um número considerável de indivíduos nos dois países que se informam pelas redes sociais, que assumem a função informativa, com os perfis de veículos de comunicação, como os que compuseram nossos corpora. Jenkins (2008) trata do fenômeno da Cultura da Convergência, em que as mídias confluem. Por exemplo, o jornal impresso tem a sua página on-line que, por sua vez, está nas redes sociais. $\mathrm{O}$ conteúdo é compartilhado pelas empresas de comunicação e, imediatamente, pelos usuários das redes em seus perfis na virtualidade. Temos, portanto, novas formas de comunicação e interação, que se dão de forma convergente entre os indivíduos.

Passamos à questão nove de nosso estudo, em que abordamos o tipo de páginas de Facebook em que os informantes acompanham as notícias sobre política. Os resultados estão nos gráficos abaixo (fig. 7 e fig. 8).

Figura 7 - gráfico questão 9 - português

\section{Em que tipo de páginas de Facebook você acompanha as notícias sobre} política?

100 respostas

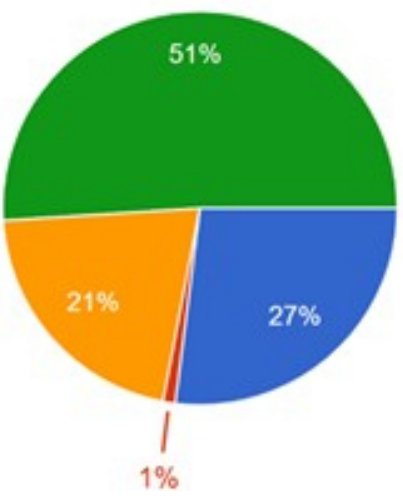

em páginas com posição politica semelhante a sua

em páginas com posiçăo politica oposta a sua

em páginas consideradas neutras. pois acredita que a imprensa não deve ter posiçăo politica

em todo tipo de páginas, pois acredita que é importante ter mais de um ponto de vista

Fonte: Lima (2019) 
Do lado brasileiro, 51\% dos participantes afirmam que se informam em todo tipo de páginas, seguido de $27 \%$ que o fazem em páginas com posição política semelhante e $21 \%$ buscam informação em páginas consideradas neutras".

Figura 8 - gráfico questão 9 - espanhol

\section{9. ¿En qué tipo de páginas de Facebook acompañás las noticias sobre política? \\ 100 respostas}

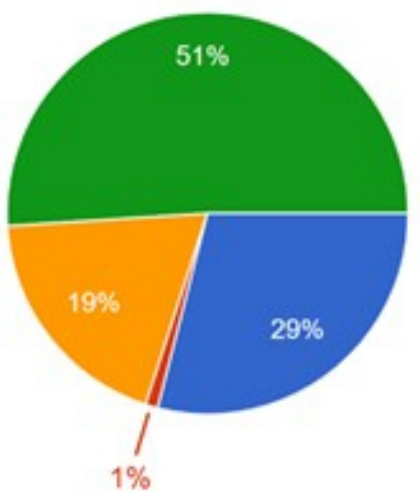

con posición politica similar a la tuya

con posición politica opuesta a la tuya

en las consideradas neutras, porque te parece que la prensa no debe tener una posición politica

en todo tipo de páginas, te parece que es importante tener más de un punto de vista

Fonte: Lima (2019)

Por sua vez, a mesma porcentagem de argentinos afirma que busca informação em todo tipo de páginas, seguido por $29 \%$ que procuram por páginas com posição política semelhante e 19\% que buscam as páginas consideradas neutras.

É importante destacar que os resultados obtidos praticamente coincidem nessa questão, inclusive com apenas $1 \%$ de informantes que afirmam recorrer às páginas com posição política oposta à sua, o que pode indicar, por parte de quase a totalidade, uma postura de evitação do confronto direto. Cremos que a escolha das opções em todo tipo de páginas e páginas consideradas neutras pode significar a intenção do usuário em ter mais de um ponto de vista e a busca por uma imprensa isenta. 


\section{CONSIDERAÇÕES FINAIS}

Neste trabalho, nosso objetivo foi trazer algumas reflexões acerca de interações em publicações sobre políticas na rede social Facebook no Brasil e na Argentina, a partir de uma perspectiva comparada no âmbito da Pragmática Sociocultural.

Considerando o convívio em uma sociedade midiatizada e o contexto político-ideológico na atualidade, temos nas redes sociais um objeto de estudo frutífero, em que podemos observar os papeis assumidos e desempenhados pelos indivíduos em interações nesse contexto.

A atual conjuntura tem facilitado o confronto nas redes sociais, dando novos contornos a oposição nós contra eles. É perceptível o clima beligerante na virtualidade, o que potencializa o enfrentamento, facilitado, muitas vezes, pela possibilidade do anonimato, pela velocidade da comunicação e seu imediatismo.

Os dados apresentados no presente artigo confirmam a nossa escolha pelas páginas de veículos de informação que têm grande alcance nas redes sociais, onde se dá o encontro dos leitores. Entretanto, é possível observar que, via de regra, nessas interações ocorrem os confrontos diretos entre os interagentes que, na maioria das vezes, apenas marcam a sua opinião e não buscam argumentar, postura que contribuiria para o engajamento na interação. Dessa forma, podemos afirmar que a bolha não se rompe e la grieta no se cierra, evidenciando a polarização político-ideológica nos dois países.

\section{REFERÊNCIAS}

BERNAL, María. El test de hábitos sociales aplicados al estudio de la descortesía. In: ABELDA, Marta; BRIZ, Antonio; CONTRERAS, Josefa; HERNÁNDEZ FLORES, Nieves; HIDALGO, Antonio. (eds.). Actas del III Coloquio Internacional del Programa EDICE - Cortesía y conversación: de lo escrito a lo oral. Valencia: Universitat deValencia, 2006, p. 623-641.

BRAVO, Diana. ¿Imagen "positiva" vs. Imagen "negativa"? Pragmática sociocultural y componentes de face. Oralia. Análisis del discurso oral, 2, 1999. 
CLARÍN. El impacto de la grieta en redes sociales: Facebook, al tope en una encuesta. Buenos Aires, 06/11/2017. Disponível em: https://www.clarin.com/politica/impacto-grietaredes-sociales-facebook-tope-encuesta_0_HySYKCaC-

.html?fbclid=IwAR0eMDq2q7ZiiqpZ5bR7M\%E2\%80\%A6 Acessado em 10/03/2019.

CORDISCO, Ariel; KAUL DE MARLANGEON, Silvia. La descortesía verbal en el contexto político-ideológico de las redes sociales. Revista de Filología, 32; enero 2014, pp. 145-162.

CUÉ, Carlos E. El final de la grieta argentina? El País. Buenos Aires, 13/11/2015.

Disponível

em:

https://elpais.com/internacional/2015/10/24/actualidad/1445703385_149986.html

Acessado em 10/03/2019.

CULPEPER, Jonathan. Impoliteness: using language to cause offence. Londres: Cambridge University Press, 2011.

JENKINS, Henry. Cultura da Convergência. São Paulo: Aleph, 2008.

HERNÁNDEZ FLORES, Nieves. Los tests de hábitos sociales y su uso en el estudio de la cortesía: una introducción. In: BRAVO, Diana (Ed.). Actas del Primer Coloquio del Programa EDICE. La perspectiva no etnocentrista de la cortesía: identidad sociocultural de las comunidades hispanohablantes. Estocolmo: Universidad de Estocolmo-Programa EDICE, 2003. p. 186-197.

KAUL DE MARLANGEON, Silvia. Descortesía de fustigación por afiliación exacerbada o refractariedad. In: BRAVO, Diana (ed.). Estudios de la (des)cortesía en español. Categorías conceptuales y aplicaciones a corpora orales y escritos, Buenos Aires: Programa EDICEDunken, 2005.

KAUL DE MARLAGEON, Silvia. Tipología del comportamiento verbal descortés en español. In: ALBELDA, Marta; BRIZ GÓMEZ, Antonio; CONTRERAS, Josefa; HERNÁNDEZ FLORES, Nieves; HIDALGO, Antonio. (eds.) Cortesía y conversación: de lo escrito a lo oral. Tercer coloquio internacional del programa EDICE, 254-266. Valencia/Estocolmo: Universidad de Valencia-Programa Edice, 2008.

LIMA, Fábio Barbosa de. Nós contra eles: a descortesia no contexto político-ideológico na rede social Facebook no Brasil e na Argentina. Tese de Doutorado. 2019. 212 f. (Letras Língua Espanhola). Faculdade de Filosofia, Letras e Ciências Humanas. Universidade de São Paulo, São Paulo.

MATEO, Juan José. "La grieta” que nos separa a los argentinos. Diario Prensa.Com.Ar. s/p. 30/12/2017. Disponível em: https://www.diarioprensa.com.ar/la-grieta-nos-separalos-argentinos/ Acessado em: 20/04.2019.

MURILLO, Jorge. Sobre la metodología de investigación en estudios sobre el discurso de la cortesía: a propósito del empleo de cuestionarios de hábitos sociales. In: ABELDA, Marta; BRIZ, Antonio, CONTRERAS, Josefa; HERNÁNDEZ FLORES, Nieves; HIDALGO, Antonio (eds.). Actas del III Coloquio Internacional del Programa EDICE Cortesía y conversación: de lo escrito a lo oral. Valencia: Universitat de Valencia, 2006, p. 53-70. 
RIBEIRO, Marcio Moretto. Antipetismo e conservadorismo no Facebook. In: GALLEGO, Ester Solano (org.). O ódio como política. A reinvenção das direitas no Brasil. São Paulo: Boitempo, 2018.

SÁEZ, Cristina. La burbuja política o cómo las redes multiplican la colisión entre quienes piensan distinto. La Vanguardia. Barcelona, 09/12/2018. Disponível em: https://www.lavanguardia.com/politica/20181209/453445541336/papel-redes-socialesradicalizacion-politica-discrepancias-twitter.html?fbclid=IwA\%E2\%80\%A6. Acessado em 15/03/2019.

VIANA, Natalia. Jovens se afastam de páginas engajadas e interagem com imprensa tradicional, revela estudo. A Pública. São Paulo, 12/03/2018. Disponível em: https://apublica.org/2018/03/jovens-se-afastam-de-paginas-engajadas-e-interagem-comimprensa-tradicional-revela-estudo/?fbclid=IwAR0e57T\%E2\%80\%A6 Acessado em 20/03/2019.

ZUCKERMAN, Ethan. Redes sociais criam bolhas ideológicas inacessíveis a quem pensa diferente. Folha de São Paulo. Caderno Ilustríssima. São Paulo. s/p. 24/09/2017. Disponível em: $\quad$ https://m.folha.uol.com.br/ilustrissima/2017/09/1920816-cada-macaco-no-seugalho---

zuckerman.shtml?fbclid=IwAR1V99S2llcKGpfEl7K4oz3CC_UOIfFxLN5BOFb43PfKDTBB0Syrsyj-9o Acessado em: 20/04/2019.

Nota do editor:

Artigo submetido para avaliação em: 30 de setembro de 2020.

Aprovado em sistema duplo cego em: 22 de dezembro de 2020. 